\title{
Isotopic Signatures of Supernova Nucleosynthesis in Presolar Silicon Carbide Grains of Type AB with Supersolar ${ }^{14} \mathrm{~N} /{ }^{15} \mathrm{~N}$ Ratios
}

\author{
Peter Hoppe (iD ${ }^{1}$, Richard J. Stancliffe ${ }^{2,6}$ (D), Marco Pignatari ${ }^{2,3,4,6}$ (D), and Sachiko Amari ${ }^{5}$ \\ ${ }^{1}$ Max Planck Institute for Chemistry, Hahn-Meitner-Weg 1, D-55128 Mainz, Germany; peter.hoppe@ mpic.de \\ ${ }^{2}$ E. A. Milne Centre for Astrophysics, University of Hull, HU6 7RX, Hull, UK \\ ${ }^{3}$ Konkoly Observatory, Konkoly Thege Miklos ut 15-17, 1121, Budapest, Hungary \\ ${ }^{4}$ Joint Institute for Nuclear Astrophysics-Center for the Evolution of the Elements (JINA-CEE), USA \\ ${ }^{5}$ McDonnell Center for the Space Sciences and Physics Department, Washington University, St. Louis, MO 63130, USA \\ Received 2019 July 26; revised 2019 October 7; accepted 2019 October 27; published 2019 December 5
}

\begin{abstract}
We report high-resolution $\mathrm{C}, \mathrm{N}, \mathrm{Al}, \mathrm{Si}$, and $\mathrm{S}$ isotope data of 38 presolar $\mathrm{SiC}$ grains of type $\mathrm{AB}$. Seventeen of these grains are of subtype $\mathrm{AB} 1\left({ }^{14} \mathrm{~N} /{ }^{15} \mathrm{~N}<440=\right.$ solar $)$ and 20 of subtype $\mathrm{AB} 2\left({ }^{14} \mathrm{~N} /{ }^{15} \mathrm{~N} \geqslant 440\right)$, previously proposed to be mainly from supernovae (AB1) and J-type carbon stars (AB2), respectively. Our data are compatible with previously obtained isotope data of $\mathrm{AB}$ grains, except that ${ }^{26} \mathrm{Al} /{ }^{27} \mathrm{Al}$ ratios of $\mathrm{AB} 1$ grains span a narrower range. The data are compared with predictions from supernova models that consider $\mathrm{H}$ ingestion into the He shell during the pre-supernova phase. In these models a mixture of explosive $\mathrm{H}$ and He burning occurs at the bottom of the He shell during passage of the supernova shock, forming the so-called O/nova zone. Mixing matter from the $\mathrm{O} /$ nova zone with matter from the overlying $\mathrm{He} / \mathrm{C}$ zone and the stellar envelope shows that the isotopic compositions and trends of both $\mathrm{AB} 1$ and $\mathrm{AB} 2$ grains can be matched within the model uncertainties. This demonstrates that supernovae should be considered as potential sources of AB2 grains, in addition to J-type carbon stars and born-again asymptotic giant branch stars, as previously proposed.
\end{abstract}

Unified Astronomy Thesaurus concepts: Circumstellar matter (241); Meteorites (1038); Nucleosynthesis (1131); Supernovae (1668)

\section{Introduction}

Primitive solar system materials, e.g., undifferentiated meteorites, interplanetary dust particles, and cometary matter returned by NASA's Stardust mission, contain small quantities of so-called presolar grains that formed in the winds of evolved stars and in the ejecta of stellar explosions (Zinner 2014). These pristine dust grains can be analyzed in terrestrial laboratories for isotopic compositions and other physical properties. These laboratory studies have provided a wealth of astrophysical information, e.g., on stellar nucleosynthesis and evolution, mixing in supernova ( $\mathrm{SN}$ ) ejecta, dust formation in stellar environments, dust processing in the interstellar medium, and the inventory of stars that contributed dust to our solar system.

Identified stardust minerals include silicon carbide $(\mathrm{SiC})$, graphite, silicon nitride, oxides (e.g., $\mathrm{MgAl}_{2} \mathrm{O}_{4}$ and $\mathrm{Al}_{2} \mathrm{O}_{3}$ ), and silicates. Most of these stardust grains were found in primitive meteorites because meteorites represent the most abundant type of extraterrestrial matter available for laboratory studies. Most abundant among the stardust minerals are silicates, which, however, were identified only $15 \mathrm{yr}$ after the discovery of carbonaceous presolar grains (Messenger et al. 2003). The reason for this is that presolar silicates, in contrast to carbonaceous presolar grains, cannot be separated from primitive meteorites by chemical treatments and only the application of high-resolution ion-imaging techniques to thin sections of primitive solar system materials made their in situ discovery possible. Because in situ ion imaging is a time-consuming technique, much less information is available on the isotopic compositions of presolar silicates than for carbonaceous presolar grains.

\footnotetext{
${ }^{6}$ NuGrid Collaboration, http://www.nugridstars.org.
}

Silicon carbide is the best-characterized presolar mineral. It was identified more than $30 \mathrm{yr}$ ago (Bernatowicz et al. 1987) because it is tagged with noble gases of anomalous isotopic compositions (Lewis et al. 1994). Subsequently, it was found that the major elements $\mathrm{C}$ and $\mathrm{Si}$, and numerous minor elements contained in presolar $\mathrm{SiC}$, have highly anomalous isotopic compositions as well, the fingerprints of nucleosynthetic processes in their parent stars. Based on the isotopic compositions of $\mathrm{C}, \mathrm{N}$, and $\mathrm{Si}, \mathrm{SiC}$ was divided into distinct populations (Zinner 2014). This includes the mainstream grains, which account for about $80 \%-90 \%$ of all grains (depending on grain size), and the minor types $\mathrm{AB}$ (originally defined as two distinct types $\mathrm{A}$ and $\mathrm{B}$ ), C, X, Y, Z, and (putative) nova grains. The mainstream grains have ${ }^{12} \mathrm{C} /{ }^{13} \mathrm{C}$ ratios between 10 and 100 (solar: 89 ), and the ${ }^{14} \mathrm{~N} /{ }^{15} \mathrm{~N}$ ratios of most of them are higher than the solar ratio of 440 , the ratio measured for the solar wind (Marty et al. 2011). In a plot of $\delta^{29} \mathrm{Si}$ versus $\delta^{30} \mathrm{Si}$, the mainstream grains lie along a straight line defined by $\delta^{29} \mathrm{Si}=1.37 \times \delta^{30} \mathrm{Si}-20$ (Zinner et al. 2007), where $\delta^{x} \mathrm{Si}=\left[\left({ }^{x} \mathrm{Si} /{ }^{28} \mathrm{Si}\right)_{\text {grain }} /\left({ }^{x} \mathrm{Si} /{ }^{28} \mathrm{Si}\right)_{\text {solar }}-1\right) \times 1000$, and $x=29$ or 30 , i.e., $\delta^{x} \mathrm{Si}$ is the per mil deviation from the solar ${ }^{x} \mathrm{Si} /{ }^{28} \mathrm{Si}$ ratio. $\delta^{30} \mathrm{Si}$ values of mainstream grains vary between about $-50 \%$ and $+150 \%$ o. The isotopic compositions of heavy elements show the signatures of slow neutron-capture nucleosynthesis (s-process, Käppeler et al. 2011), which points toward low-mass (1.5-3 $M_{\odot}$ ) asymptotic giant branch (AGB) stars of about solar or supersolar metallicity as parent stars (e.g., Lugaro et al. 2018, and references therein). The minor type $\mathrm{Y}$ and $\mathrm{Z}$ grains (a few $\%$ of all $\mathrm{SiC}$ grains, depending on grain size), which fall to the ${ }^{30} \mathrm{Si}$-rich side of the Si mainstream line, were also proposed to originate from low-mass AGB stars, but with metallicities lower than solar (Hoppe et al. 1997; Amari et al. 2001b). This low-metallicity scenario, however, 
was recently questioned (Liu et al. 2019). The type C ( $\sim 0.1 \%$ of all $\mathrm{SiC}$ grains) and $\mathrm{X}$ grains $(\sim 1 \%$ of all $\mathrm{SiC}$ grains $)$ are believed to originate from core-collapse supernovae (CCSNe; Amari et al. 1992; Hoppe et al. 1996b; Nittler et al. 1996; Gyngard et al. 2010). These grains show strong depletions (X grains) or enrichments ( $\mathrm{C}$ grains) in the heavy $\mathrm{Si}$ isotopes. Their ${ }^{12} \mathrm{C} /{ }^{13} \mathrm{C}$ ratios span a large range from $<10$ to $>10,000$; other characteristic features of $\mathrm{X}$ and $\mathrm{C}$ grains are enrichments in ${ }^{15} \mathrm{~N}$ and high initial ${ }^{26} \mathrm{Al} /{ }^{27} \mathrm{Al}$ ratios of typically $>0.1$. Putative nova grains ( $\sim 0.1 \%$ of all $\mathrm{SiC}$ grains) have low ${ }^{12} \mathrm{C} /{ }^{13} \mathrm{C}$ ratios of $<10$, low ${ }^{14} \mathrm{~N} /{ }^{15} \mathrm{~N}$ ratios of $<40$, and high initial ${ }^{26} \mathrm{Al} /{ }^{27} \mathrm{Al}$ ratios of up to 0.2 (Amari et al. 2001a); their origins in the outflows of nova explosions, however, were questioned and $\mathrm{SNe}$ were proposed for at least some of the putative nova grains instead (Nittler \& Hoppe 2005; Pignatari et al. 2015; Liu et al. 2017a; Hoppe et al. 2018b).

The type $\mathrm{AB}$ grains constitute a few percent of all $\mathrm{SiC}$ grains. AB grains have ${ }^{12} \mathrm{C} /{ }^{13} \mathrm{C} \lesssim 10$, a large range of ${ }^{14} \mathrm{~N} /{ }^{15} \mathrm{~N}$ ratios from $\sim 30$ to $10,000, \mathrm{Si}$-isotopic compositions along the $\mathrm{Si}$ mainstream line, and higher initial ${ }^{26} \mathrm{Al} /{ }^{27} \mathrm{Al}$ ratios than the mainstream grains (Zinner 2014). AB grains were subdivided into two subtypes depending on the $\mathrm{N}$-isotopic ratio. $\mathrm{AB}$ grains with isotopically heavy $\mathrm{N}\left({ }^{14} \mathrm{~N} /{ }^{15} \mathrm{~N}<440=\right.$ solar $)$ have been named $A B 1$, and those with light $N\left({ }^{14} \mathrm{~N} /{ }^{15} \mathrm{~N} \geqslant 440\right)$ are called AB2 (Liu et al. 2017a). The origin of AB grains is still a matter of debate. Proposed major stellar sources include bornagain AGB stars (Amari et al. 2001b) and J-type carbon stars (Liu et al. 2017b) for AB2 grains, and SNe for AB1 grains (Liu et al. 2017a). Several theoretical models are available today for SNe and AGB stars, and while several uncertainties still remain, nucleosynthesis results can be analyzed and compared with observations. On the other hand, from an evolutionary point of view, J-type $\mathrm{C}$ stars are still somewhat of a mystery: We do not know how they form, nor what they evolve into. Recent population synthesis modeling by Sengupta et al. (2013) suggested these stars formed in nova systems where the companion accreted nova ejecta, and subsequently merged with the white dwarf. However, little is known about the nucleosynthetic signatures of these events. Sengupta et al. (2013) explored the possibility that J-type carbon stars could evolve to an AGB-like phase, where they would eject material in a similar way to normal AGB stars. If their initial mass and metallicity would allow these stars to avoid third dredge-up, they could conceivably produce dust grains in a similar manner to AGB stars, but with $\mathrm{AB}$ grain-like compositions. However, if third dredge-up does happen, the composition would likely become similar to those of normal AGB stars because of high ${ }^{12} \mathrm{C}$ production. Therefore it is still unclear if J-type $\mathrm{C}$ stars can condense $\mathrm{AB} \mathrm{SiC}$ grains at all, making this scenario highly speculative, and with no comprehensive nucleosynthesis calculations to compare it with.

Here, we report on high spatial resolution measurements of C-, N-, Mg-Al-, Si-, and S-isotopic compositions of 38 submicrometer-sized $\mathrm{AB}$ grains from the Murchison CM2 meteorite by NanoSIMS ion imaging. Particular care was used to exclude contamination on or around grains and measurements of grain aggregates (containing two or more SiC grains), as this can seriously affect the interpretation of the isotope data of $\mathrm{AB}$ grains. The main goal of our study is to explore whether $\mathrm{SNe}$ could account for the isotopic signatures of both $\mathrm{AB} 1$ and $\mathrm{AB} 2$ grains. This would provide an alternative or complementary scenario to J-Type $\mathrm{C}$ stars being the dominant sources of AB2 grains, as proposed by Liu et al. (2017b). For this purpose, we compare the isotope data of $\mathrm{AB}$ grains with predictions from SN models of Pignatari et al. (2015), who consider $\mathrm{H}$ ingestion into the He shell during the pre-SN phase. Except for one specific grain, we do not try to find exact matches for the isotopic compositions of individual $\mathrm{AB}$ grains by specific $\mathrm{SN}$ mixtures, but rather explore whether the trends and ranges seen in the isotope data of $\mathrm{AB}$ grains can be reproduced. Preliminary data of this work were published in two conference proceedings (Hoppe et al. 2019a, 2019b).

\section{Experimental}

Hundreds of $\mathrm{SiC}$ grains from the Murchison separate KJD (median size: $0.81 \mu \mathrm{m}$; Amari et al. 1994), dispersed on a clean gold foil, were screened by $\mathrm{C}$ and $\mathrm{Si}$ ion-imaging with the NanoSIMS ion probe at the Max Planck Institute for Chemistry. For this purpose, a focused $\mathrm{Cs}^{+}$primary ion beam $(\sim 1 \mathrm{pA}, 100 \mathrm{~nm})$ was rastered over $13630 \times 30 \mu \mathrm{m}^{2}$ sized areas on the gold foil and negative secondary ion images of ${ }^{12} \mathrm{C}$, ${ }^{13} \mathrm{C},{ }^{28} \mathrm{Si},{ }^{29} \mathrm{Si}$, and ${ }^{30} \mathrm{Si}$ were recorded in multi-collection $(256 \times 256$ pixels, 15,000 $\mu \mathrm{s} / \mathrm{pixel})$. Visual inspection of ion images identified $38 \mathrm{AB}$ grains, based on their large ${ }^{13} \mathrm{C}$ enrichments. Follow-up measurements with high spatial resolution and a raster only slightly larger than the grain sizes of $\mathrm{C}, \mathrm{N}$ (measured as $\mathrm{CN}$ ), $\mathrm{Mg}-\mathrm{Al}, \mathrm{Si}$, and $\mathrm{S}$ isotopes were conducted in three sessions: (i) Measurement of $\mathrm{C}$ and $\mathrm{Si}$ isotopes with the same detector setup as described above on 38 $\mathrm{AB}$ grains, employing the $\mathrm{Cs}^{+}$primary ion source $(\sim 1 \mathrm{pA}$, $100 \mathrm{~nm}$, raster $1.5 \times 1.5-4 \times 4 \mu \mathrm{m}^{2}$ ). (ii) Measurement of negative secondary ions of ${ }^{12} \mathrm{C}^{14} \mathrm{~N},{ }^{12} \mathrm{C}^{15} \mathrm{~N},{ }^{28} \mathrm{Si}$ or ${ }^{29} \mathrm{Si},{ }^{32} \mathrm{~S}$, and ${ }^{34} \mathrm{~S}$ on $37 \mathrm{AB}$ grains, employing the $\mathrm{Cs}^{+}$primary ion source $\left(\sim 1 \mathrm{pA}, 100 \mathrm{~nm}\right.$, raster raster $\left.1.5 \times 1.5-3 \times 3 \mu \mathrm{m}^{2}\right)$. (iii) Measurement of positive secondary ions of ${ }^{24} \mathrm{Mg},{ }^{25} \mathrm{Mg}$, ${ }^{26} \mathrm{Mg},{ }^{27} \mathrm{Al}$, and ${ }^{28} \mathrm{Si}$ on $34 \mathrm{AB}$ grains, employing the recently installed high-resolution Hyperion $\mathrm{O}^{-}$primary ion source $\left(\sim 3 \mathrm{pA}, 100 \mathrm{~nm}\right.$, raster $1.5 \times 1.5-3 \times 3 \mu \mathrm{m}^{2}$; see Hoppe et al. 2018a; Nittler et al. 2018). The relative $\mathrm{Al}^{+} / \mathrm{Mg}^{+}$sensitivity factor (1.56), required to calculate initial ${ }^{26} \mathrm{Al} /{ }^{27} \mathrm{Al}$ ratios, was taken from Hoppe et al. (2010).

Ion images of ${ }^{12} \mathrm{C},{ }^{13} \mathrm{C} /{ }^{12} \mathrm{C}$, and ${ }^{27} \mathrm{Al}$ along with the SEM image of $\mathrm{SiC}$ grain KJD-102 are displayed in Figure 1. The $\mathrm{C}$-isotopic ratio image illustrates the importance of high spatial resolution measurements, as the object seen in the SEM image apparently is composed of two distinct $\mathrm{SiC}$ grains: one $\mathrm{AB}$ grain with its characteristic high ${ }^{13} \mathrm{C}$ enrichment, and in this case, also high $\mathrm{Al}$ concentration; and another $\mathrm{SiC}$ grain with a lower ${ }^{13} \mathrm{C} /{ }^{12} \mathrm{C}$ ratio and low $\mathrm{Al}$ concentration. Without a sufficient resolution of these two grains, their combined ion signals would still show the characteristic $\mathrm{C}$-isotopic ratio of $\mathrm{AB}$ grains $\left({ }^{12} \mathrm{C} /{ }^{13} \mathrm{C}<10\right)$, but the isotopic signatures of the $\mathrm{AB}$ grain would be distorted and interpretations misled.

\section{Results}

Carbon-, N-, Al-, Si-, and S-isotopic compositions of the 38 AB grains from this study are presented in Table 1 and in Figures 2-4. Except for one outlier, grain KJD-134b, which has ${ }^{12} \mathrm{C} /{ }^{13} \mathrm{C}=15.6$ and ${ }^{14} \mathrm{~N} /{ }^{15} \mathrm{~N}=36,{ }^{12} \mathrm{C} /{ }^{13} \mathrm{C}$ ratios are between 1.6 and 10 and ${ }^{14} \mathrm{~N} /{ }^{15} \mathrm{~N}$ ratios between 50 and 10,000 , 


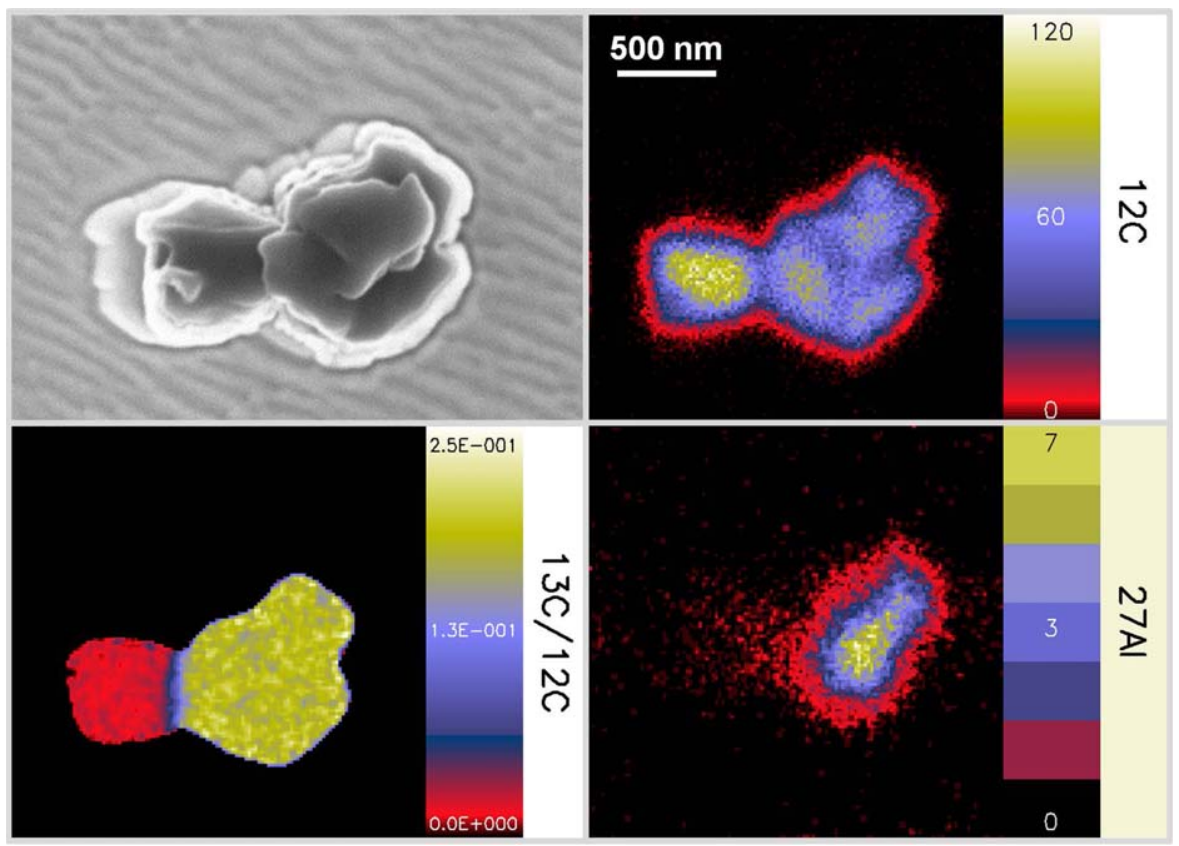

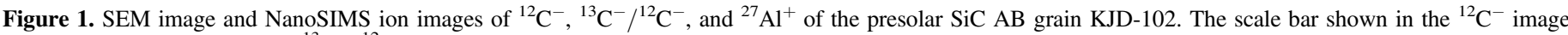

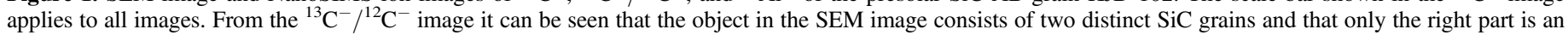
$\mathrm{SiC}$ grain of type $\mathrm{AB}$.

falling well within the ranges of previously studied $\mathrm{AB}$ grains (Figure 2). Seventeen of the grains are of type AB1 (including KJD-134b), and 20 of type AB2; for one grain (KJD-101) we lack $\mathrm{N}$ isotope data, i.e., it cannot be assigned to one of the $\mathrm{AB}$ subtypes. In Figure 2 grain KJD-134b plots in the area occupied by putative nova and $\mathrm{SN}$ grains. While its ${ }^{26} \mathrm{Al} /{ }^{27} \mathrm{Al}$ ratio $(0.13$, which is the highest value among our studied AB grains) is also compatible with those of putative nova or SN grains, its $\mathrm{Si}$-isotopic composition is that of $\mathrm{AB}$ grains, which makes a clear assignment to one of the grain groups impossible. As we do not wish to define a new subtype for grain KJD-134b, we assign it here to subtype AB1. In most cases, $\mathrm{Mg}$ was found to be dominated by ${ }^{26} \mathrm{Mg}$, which is clear evidence for ${ }^{26} \mathrm{Al}$ decay (half-life 716,000 yr). Inferred initial ${ }^{26} \mathrm{Al} /{ }^{27} \mathrm{Al}$ ratios are between $10^{-4}$ and 0.13 . There is a rough negative correlation between ${ }^{26} \mathrm{Al} /{ }^{27} \mathrm{Al}$ and ${ }^{14} \mathrm{~N} /{ }^{15} \mathrm{~N}$ for $\mathrm{AB} 1$ grains (Figure 3). Some of the AB2 grains follow this trend, but overall, AB2 grains exhibit a larger scatter in the ${ }^{26} \mathrm{Al} /{ }^{27} \mathrm{Al}$ versus ${ }^{14} \mathrm{~N} /{ }^{15} \mathrm{~N}$ representation. Silicon-isotopic compositions plot along the Si mainstream line, with $\delta^{29} \mathrm{Si}$ values between $-80 \%$ and $+230 \%$, and $\delta^{30} \mathrm{Si}$ values between $-50 \%$ and $+160 \%$ o (Figure 4). There is no clear distinction between the $\mathrm{Si}$-isotopic compositions of $\mathrm{AB} 1$ and $\mathrm{AB} 2$ grains. Weighted linear regressions according to York-Mahon (Mahon 1996; York 1969) give $\delta^{29} \mathrm{Si}=(1.43 \pm 0.16) \times \delta^{30} \mathrm{Si}-(14 \pm 11)$ for $\mathrm{AB} 1$ grains and $(1.66 \pm 0.32) \times \delta^{30} \mathrm{Si}-(19 \pm 16)$ for $\mathrm{AB} 2$ grains (the reduced chi square values of 1.12 and 3.2, respectively, for the fits are included in the errors), i.e., the slopes and intercepts are fully compatible with the Si mainstream line. The ${ }^{34} \mathrm{~S} /{ }^{32} \mathrm{~S}$ ratios of all $\mathrm{AB}$ grains are normal within $\sim 2 \sigma$; The $13 \mathrm{AB} 2$ grains with $\mathrm{S} / \mathrm{Si}<0.01$ have on average $\delta^{34} \mathrm{~S}=-43 \pm 31 \%$ and 11 out of the 13 grains have $\delta^{34} \mathrm{~S}<0$. The $10 \mathrm{AB} 1$ grains with $\mathrm{S} / \mathrm{Si}<0.01$ have on average $\delta^{34} \mathrm{~S}=1 \pm 44 \%$ and 5 out of the 10 grains have $\delta^{34} \mathrm{~S}<0$.

\section{Discussion}

\subsection{Comparison with Isotope Data of $A B$ Grains from Previous Studies}

In the literature, simultaneous $\mathrm{C}, \mathrm{N}, \mathrm{Mg}-\mathrm{Al}$, and $\mathrm{Si}$ isotope data exist for 88 AB grains (Hoppe et al. 1994, 2010; Huss et al. 1997; Amari et al. 2001b; Liu et al. 2017b), i.e., our data set, comprising $34 \mathrm{AB}$ grains with $\mathrm{C}, \mathrm{N}, \mathrm{Mg}-\mathrm{Al}$, and $\mathrm{Si}$ isotope data, has increased this number by almost $40 \%$. A comparison of our new isotope data for $\mathrm{AB} 1$ and $\mathrm{AB} 2$ grains with those previously obtained shows good agreement in general (Figures 2 and 4), except for the combined ${ }^{26} \mathrm{Al} /{ }^{27} \mathrm{Al}$ and ${ }^{14} \mathrm{~N} /{ }^{15} \mathrm{~N}$ data of $\mathrm{AB} 1$ grains (Figure 3 ). For the latter, many of the ${ }^{26} \mathrm{Al} /{ }^{27} \mathrm{Al}$ ratios from previous studies are lower than the new data presented here. This cannot be explained by different $\mathrm{Al}^{+} / \mathrm{Mg}^{+}$sensitivity factors inferred in the different SIMS studies, but points toward a higher level of unrecognized $\mathrm{Al}$ contamination in part of the previous data, as discussed by Groopman et al. (2015).

\subsection{AB Grains in the Context of J-type C Stars and Born-again $A G B$ Stars}

Liu et al. (2017b) have favored J-type C stars as dominant sources of $\mathrm{AB} 2$ grains based on observed $\mathrm{C}$ - and $\mathrm{N}$-isotopic compositions and missing s-process signatures. J-type $\mathrm{C}$ stars have ${ }^{12} \mathrm{C} /{ }^{13} \mathrm{C}$ ratios between $\sim 2$ and 12 (Ohnaka \& Tsuji 1999) and ${ }^{14} \mathrm{~N} /{ }^{15} \mathrm{~N}$ ratios between 900 and 3200 (Hedrosa et al. 2013), as inferred from spectroscopic observations, and in agreement with AB2 grains. This makes J-type C stars plausible sources of AB2 grains. However, as we pointed out in the Introduction section, we do not know much about these objects, and there are no nucleosynthesis yields from these objects to compare with measurements on presolar grains, which makes a final judgment difficult. 
Table 1

Carbon-, N-, Si-, and S-isotopic Compositions and Inferred ${ }^{26} \mathrm{Al} /{ }^{27} \mathrm{Al}$ Ratios of Presolar SiC AB Grains from Murchison Separate KJD

\begin{tabular}{|c|c|c|c|c|c|c|c|}
\hline Grain & Type & ${ }^{12} \mathrm{C} /{ }^{13} \mathrm{C}$ & ${ }^{14} \mathrm{~N} /{ }^{15} \mathrm{~N}$ & ${ }^{26} \mathrm{Al} /{ }^{27} \mathrm{Al}\left(10^{-3}\right)$ & $\delta^{29} \mathrm{Si}(\% o)$ & $\delta^{30} \mathrm{Si}(\% o)$ & $\delta^{34} \mathrm{~S}(\% o)$ \\
\hline KJD-101 & $\mathrm{AB}$ & $4.34 \pm 0.06$ & & & $141 \pm 37$ & $114 \pm 45$ & \\
\hline KJD-102 & $\mathrm{AB} 2$ & $5.82 \pm 0.02$ & $552 \pm 42$ & $10.6 \pm 1.4$ & $121 \pm 5$ & $87 \pm 6$ & $26 \pm 25$ \\
\hline KJD-103 & $\mathrm{AB} 2$ & $3.94 \pm 0.01$ & $3750 \pm 400$ & $2.4 \pm 0.2$ & $69 \pm 6$ & $44 \pm 7$ & $21 \pm 61$ \\
\hline KJD-108a & $\mathrm{AB} 1$ & $2.60 \pm 0.01$ & $122 \pm 9$ & $3.5 \pm 1.0$ & $71 \pm 10$ & $64 \pm 12$ & $164 \pm 254$ \\
\hline KJD-108b & $\mathrm{AB} 2$ & $8.63 \pm 0.07$ & $1217 \pm 279$ & $<0.56$ & $10 \pm 11$ & $40 \pm 13$ & $-229 \pm 261$ \\
\hline KJD-111 & $\mathrm{AB} 2$ & $9.88 \pm 0.09$ & $819 \pm 71$ & $<0.48$ & $81 \pm 13$ & $74 \pm 16$ & $-32 \pm 165$ \\
\hline KJD-121 & $\mathrm{AB} 1$ & $8.01 \pm 0.07$ & $353 \pm 49$ & $<3.9$ & $59 \pm 14$ & $53 \pm 17$ & $205 \pm 189$ \\
\hline KJD-123 & $\mathrm{AB} 2$ & $8.88 \pm 0.05$ & $964 \pm 201$ & $5.2 \pm 0.9$ & $84 \pm 9$ & $5 \pm 11$ & $-60 \pm 114$ \\
\hline KJD-134a & $\mathrm{AB} 2$ & $6.33 \pm 0.14$ & $3254 \pm 679$ & $5.5 \pm 0.4$ & $29 \pm 44$ & $69 \pm 54$ & $-5 \pm 58$ \\
\hline KJD-134b & $\mathrm{AB} 1$ & $15.57 \pm 0.84$ & $36 \pm 2$ & $127.7 \pm 4.3$ & $-2 \pm 74$ & $-41 \pm 89$ & $16 \pm 111$ \\
\hline KJD-135 & $\mathrm{AB} 1$ & $1.94 \pm 0.01$ & $89 \pm 4$ & $9.2 \pm 1.5$ & $66 \pm 10$ & $26 \pm 12$ & $13 \pm 44$ \\
\hline KJD-136 & AB2 & $8.74 \pm 0.08$ & $1640 \pm 328$ & $0.36 \pm 0.1$ & $34 \pm 14$ & $27 \pm 18$ & $-74 \pm 111$ \\
\hline KJD-174 & $\mathrm{AB} 1$ & $2.48 \pm 0.03$ & $51 \pm 4$ & $21.5 \pm 6.0$ & $-22 \pm 35$ & $96 \pm 45$ & $54 \pm 154$ \\
\hline KJD-176 & $\mathrm{AB} 1$ & $2.44 \pm 0.02$ & $123 \pm 34$ & & $-50 \pm 27$ & $-17 \pm 34$ & $809 \pm 626$ \\
\hline KJD-17a & $\mathrm{AB} 1$ & $3.19 \pm 0.01$ & $171 \pm 6$ & $9.7 \pm 0.5$ & $72 \pm 9$ & $62 \pm 10$ & $52 \pm 82$ \\
\hline KJD-17b & $\mathrm{AB} 1$ & $4.16 \pm 0.05$ & $221 \pm 14$ & $8.5 \pm 1.1$ & $-16 \pm 29$ & $34 \pm 37$ & $115 \pm 71$ \\
\hline KJD-180 & $\mathrm{AB} 1$ & $3.09 \pm 0.01$ & $84 \pm 2$ & $5.4 \pm 0.3$ & $82 \pm 9$ & $79 \pm 11$ & $-8 \pm 78$ \\
\hline KJD-181 & $\mathrm{AB} 2$ & $4.82 \pm 0.02$ & $1787 \pm 565$ & $11.7 \pm 4.1$ & $-47 \pm 11$ & $-53 \pm 13$ & $-245 \pm 123$ \\
\hline KJD-183 & AB2 & $5.38 \pm 0.03$ & $817 \pm 366$ & $2.9 \pm 2.1$ & $128 \pm 12$ & $91 \pm 14$ & $-15 \pm 155$ \\
\hline KJD-22 & $\mathrm{AB} 2$ & $9.92 \pm 0.10$ & $740 \pm 112$ & $6.1 \pm 0.8$ & $127 \pm 15$ & $107 \pm 18$ & $226 \pm 109$ \\
\hline KJD-23 & $\mathrm{AB} 1$ & $3.05 \pm 0.01$ & $116 \pm 5$ & $8.5 \pm 0.8$ & $-2 \pm 9$ & $2 \pm 11$ & $-108 \pm 107$ \\
\hline KJD-27 & $\mathrm{AB} 2$ & $5.16 \pm 0.04$ & $958 \pm 114$ & $2.7 \pm 0.3$ & $-3 \pm 17$ & $-31 \pm 21$ & $120 \pm 56$ \\
\hline KJD-30 & $\mathrm{AB} 2$ & $4.21 \pm 0.02$ & $833 \pm 85$ & $6.0 \pm 0.5$ & $49 \pm 12$ & $39 \pm 15$ & $-93 \pm 85$ \\
\hline KJD-32 & $\mathrm{AB} 1$ & $4.13 \pm 0.05$ & $310 \pm 21$ & $6.9 \pm 0.8$ & $225 \pm 24$ & $146 \pm 28$ & $-7 \pm 153$ \\
\hline KJD-33 & $\mathrm{AB} 1$ & $4.32 \pm 0.04$ & $82 \pm 5$ & $12.0 \pm 1.3$ & $-78 \pm 16$ & $-34 \pm 20$ & $-73 \pm 85$ \\
\hline
\end{tabular}

Note. Errors are $1 \sigma$. Upper limits of ${ }^{26} \mathrm{Al} /{ }^{27} \mathrm{Al}$ are given when $1 \sigma$ errors are larger than $50 \%$ and are based on $2 \sigma$ errors. $\delta^{i} \mathrm{X}=\left[\left({ }^{i} \mathrm{X} /{ }^{j} \mathrm{X}\right)\right.$ grain $\left./\left({ }^{i} \mathrm{X} /{ }^{j} \mathrm{X}\right)_{\text {std }}-1\right] \times 1000$; ${ }^{j} \mathrm{X}={ }^{28} \mathrm{Si}$ or ${ }^{32} \mathrm{~S}$ and $\left({ }^{29} \mathrm{Si} /{ }^{28} \mathrm{Si}\right)_{\text {std }}=0.050804,\left({ }^{30} \mathrm{Si} /{ }^{28} \mathrm{Si}\right)_{\text {std }}=0.033532$, and $\left({ }^{34} \mathrm{~S} /{ }^{32} \mathrm{~S}\right)_{\text {std }}=0.0441626$.

Early R-type C stars and CO novae have been considered as potential sources of AB2 grains as well, but Liu et al. (2017b) pointed out that their low abundances make significant contributions to the AB2 grain population unlikely. Born-again AGB stars, which are stars that have experienced either a late or very late thermal pulse and subsequently returned to the AGB (see Herwig 2005 for a review), were excluded by Liu et al. (2017b) as a dominant source of AB2 grains because 11 out of the 12 studied AB2 grains showed about normal (solar) isotopic compositions of heavy elements, which is incompatible with the predicted large isotopic anomalies from the s-process or intermediate neutron-capture nucleosynthesis (iprocess, Herwig et al. 2011) that would be expected in dust from such stars. While the born-again AGB star Sakurai's object showed i-process signatures (Herwig et al. 2011), it cannot be excluded that other $\mathrm{H}$-ingestion events in post-AGB stars would not activate the i-process. Indeed, $\mathrm{H}$-ingestion events could cause the He intershell region to become quickly unstable, following global violent oscillations (Herwig et al. 2014), before the ${ }^{13} \mathrm{C}$ neutron source has enough time to produce heavy elements. Furthermore, in case of a low-mass star progenitor with mass lower than $1.5 M_{\odot}$, the s-process enrichment from the previous AGB evolution would also have been extremely mild and difficult to measure. Therefore, we point out that post-AGB stars should not be completely ruled out as potential sources of at least some AB2 grains without neutron-capture nucleosynthesis signatures.

\subsection{AB Grains in the Context of Supernova Models}

Low ${ }^{12} \mathrm{C} /{ }^{13} \mathrm{C}$ ratios are the signature of hydrostatic and explosive hydrogen burning (e.g., Jose \& Hernanz 1998; Rauscher et al. 2002; Wiescher et al. 2010, and references therein). While explosive $\mathrm{H}$ burning produces much ${ }^{15} \mathrm{~N}$, i.e., low ${ }^{14} \mathrm{~N} /{ }^{15} \mathrm{~N}$ ratios, hydrostatic $\mathrm{H}$ burning results in high ${ }^{14} \mathrm{~N} /{ }^{15} \mathrm{~N}$ ratios. Explosive $\mathrm{H}$ burning occurs in novae and $\mathrm{SNe}$, which were considered as potential stellar sources for presolar 


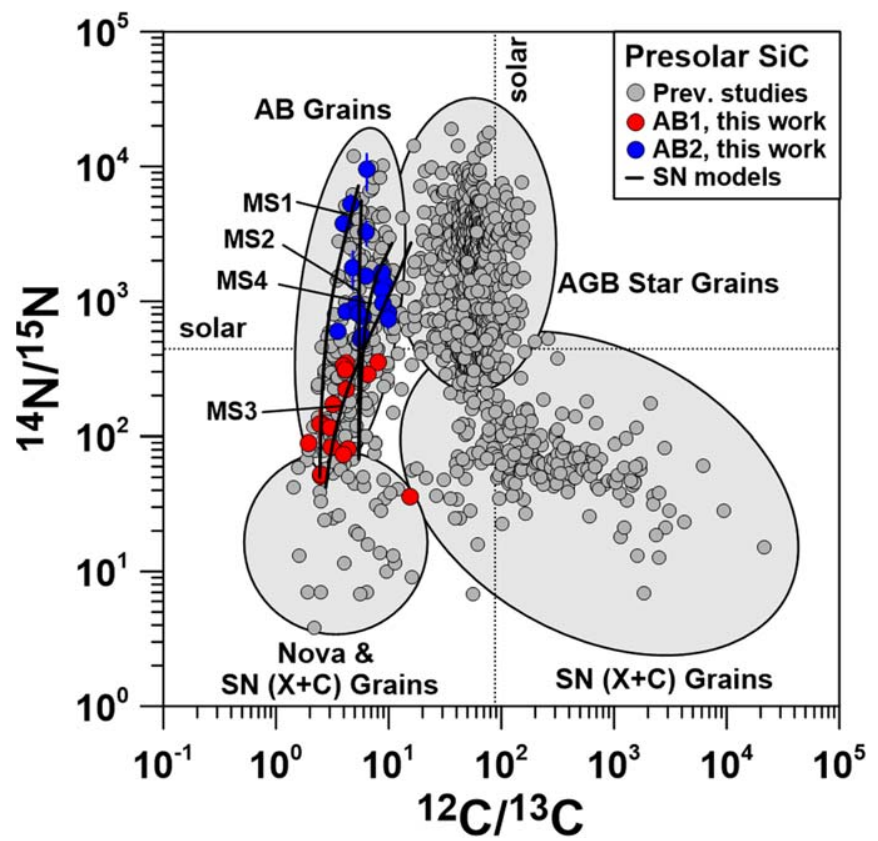

Figure 2. Carbon- and $\mathrm{N}$-isotopic compositions of $37 \mathrm{SiC} \mathrm{AB}$ grains from Murchison separate KJD. AB1 grains $\left({ }^{14} \mathrm{~N} /{ }^{15} \mathrm{~N}<440\right)$ are shown in red and AB2 grains $\left({ }^{14} \mathrm{~N} /{ }^{15} \mathrm{~N} \geqslant 440\right)$ in blue. Errors are $1 \sigma$. Selected literature data of $\mathrm{SiC}$ grains from all $\mathrm{SiC}$ populations (Hoppe et al. 1994, 1996a, 2000, 2010; Nittler 1996; Huss et al. 1997; Amari et al. 2001a, 2001b; Lin et al. 2002; Besmehn \& Hoppe 2003; Nittler \& Hoppe 2005; Marhas et al. 2008; Xu et al. 2015; Liu et al. 2016, 2017a, 2017b, 2018) are given in gray for comparison. The solar system isotopic compositions are shown by dashed lines. Predictions for four SN mixing models are shown as black solid lines. These models consider mixing of matter from the $\mathrm{O} /$ nova and $\mathrm{He} / \mathrm{C}$ zones in SN models 25T-H and 25T-H10 (Pignatari et al. 2015) with matter from the envelopes in models 25T-H and 25T-H10 (models MS1 and MS2), or alternatively, with matter from the envelope of a $15 M_{\odot}$ SN (Pignatari et al. 2013; models MS3 and MS4).

SiC grains with enhanced (relative to solar) ${ }^{15} \mathrm{~N}$ abundances, namely, putative nova grains (Amari et al. 2001a), the X and C grains (e.g., Amari et al. 1992; Nittler et al. 1996; Hoppe et al. 2000, 2010; Lin et al. 2010; Pignatari et al. 2013, 2015; Xu et al. 2015; Gyngard et al. 2018), and about half of the AB grains, namely, subtype AB1 (Liu et al. 2016, 2017a). It was pointed out by Liu et al. (2017a) that novae are unlikely sources of $\mathrm{AB} 1$ grains and that $\mathrm{AB} 1$ grains most likely formed in the ejecta of $\mathrm{SN}$ explosions.

Here, we explore whether $\mathrm{AB}$ grains with isotopically light nitrogen, i.e., those of subtype $A B 2$, which have ${ }^{14} \mathrm{~N} /{ }^{15} \mathrm{~N} \geqslant 440$, could originate from $\mathrm{SNe}$ as well. We compare our results for $\mathrm{AB}$ grains, along with those from the literature, with $\mathrm{SN}$ model predictions by Pignatari et al. (2015), which have previously been used to account for the isotope data of AB1, C, and X grains (Liu et al. 2017a; Hoppe et al. 2018b).

Pignatari et al. (2015) provide isotope data for a set of $25 M_{\odot}$ CCSNe of solar metallicity that experienced $\mathrm{H}$ ingestion into the He shell prior to the explosion. During the final stages of the massive star progenitor, the energy generation at the bottom of the convective He-burning shell becomes progressively unstable until convection is switched off. In the meantime, $\mathrm{H}$ starts to be ingested from more external layers into regions where the convective He shell was located. In the model, the convective $\mathrm{He}$ shell does not reignite before the CCSN explosion, leaving a trace of $\mathrm{H}$ in the $\mathrm{He}$ shell, together with significant ${ }^{13} \mathrm{C}$ and ${ }^{14} \mathrm{~N}$ enrichments (Pignatari et al. 2015).

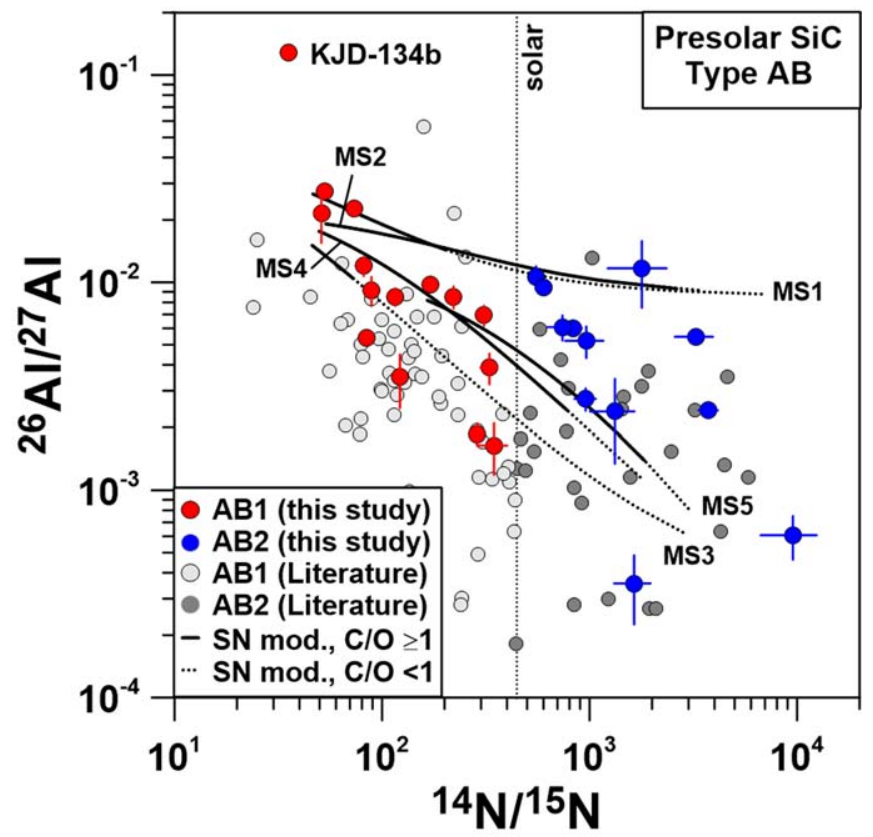

Figure 3. The ${ }^{26} \mathrm{Al} /{ }^{27} \mathrm{Al}$ and ${ }^{14} \mathrm{~N} /{ }^{15} \mathrm{~N}$ ratios of $28 \mathrm{SiC} \mathrm{AB}$ grains from Murchison separate KJD with relative $1 \sigma$ errors for ${ }^{26} \mathrm{Al} /{ }^{27} \mathrm{Al}$ ratios smaller than $50 \%$. AB1 grains $\left({ }^{14} \mathrm{~N} /{ }^{15} \mathrm{~N}<440\right)$ are shown in red and $\mathrm{AB} 2$ grains $\left({ }^{14} \mathrm{~N} /{ }^{15} \mathrm{~N} \geqslant 440\right)$ in blue. Errors are $1 \sigma$. Literature data of $\mathrm{SiC} \mathrm{AB}$ grains (Hoppe et al. 1994, 2010; Huss et al. 1997; Amari et al. 2001b; Liu et al. 2017a) are given in gray for comparison. The solar system ${ }^{14} \mathrm{~N} /{ }^{15} \mathrm{~N}$ ratio is shown by the dashed line. Predictions for the four SN mixing models from Figure 2 (models MS1-4), and in addition a mixing model that considers matter from the $\mathrm{O} /$ nova and $\mathrm{He} / \mathrm{C}$ zones in SN model 25T-H20 (Pignatari et al. 2015) and matter from the envelope of a $15 M_{\odot}$ SN (Pignatari et al. 2013; model MS5), are shown as black lines. Solid lines represent mixtures with $\mathrm{C} / \mathrm{O} \geqslant 1$ and dotted lines those with $\mathrm{C} / \mathrm{O}<1$.

Supernova models considered in this work are 25T-H, 25TH10, and 25T-H20, according to the naming scheme used by Pignatari et al. (2015). Model 25T-H considers $1.2 \% \mathrm{H}$ left in the $\mathrm{He}$ shell layers, consistent with the original $25 M_{\odot}$ progenitor (Pignatari et al. 2016). In models 25T-Hx, hydrogen concentrations are reduced by a factor of $x$, i.e., models $25 \mathrm{~T}$ $\mathrm{H} 10$ and $25 \mathrm{~T}-\mathrm{H} 20$ consider $0.12 \%$ and $0.06 \%$ of $\mathrm{H}$ in the $\mathrm{He}$ shell. Compared to the original $25 M_{\odot}$ stellar simulations, these models use artificially increased temperature and density in the He shell to mimic the temperature and density evolution of a $15 M_{\odot}$ SN during the SN explosion (see discussion in Pignatari et al. 2015 for details).

Explosive $\mathrm{H}$ burning occurs at the bottom of the $\mathrm{He}$ shell during passage of the $\mathrm{SN}$ shock, together with explosive $\mathrm{He}$ burning. This leads to unique elemental and isotopic patterns. In these models, He shell ejecta can be classified into three distinct zones: At the bottom, a thin $\left(<0.04 M_{\odot}\right) \mathrm{C} / \mathrm{Si}$ zone, and above the $\mathrm{O} /$ nova and $\mathrm{He} / \mathrm{C}$ zones. In contrast to the underlying and overlying $\mathrm{Si} / \mathrm{C}$ and $\mathrm{He} / \mathrm{C}$ zones, the $\mathrm{O} /$ nova zone has $\mathrm{C} / \mathrm{O}<1$. Most of the $\mathrm{O} /$ nova zone and the bottom of the $\mathrm{He} / \mathrm{C}$ zone exhibit low ${ }^{12} \mathrm{C} /{ }^{13} \mathrm{C},{ }^{14} \mathrm{~N} /{ }^{15} \mathrm{~N}$, and high ${ }^{26} \mathrm{Al} /{ }^{27} \mathrm{Al}$ ratios, a signature typical of nova nucleosynthesis (e.g., José \& Hernanz 2007; Denissenkov et al. 2014; Figure 5). The $\mathrm{O} /$ nova zone extends from 6.82 to $7.16 M_{\odot}(25 \mathrm{~T}-\mathrm{H})$ and from 6.85 to $7.00 M_{\odot}(25 \mathrm{~T}-\mathrm{H} 10,25 \mathrm{~T}-\mathrm{H} 20)$. Its size would typically decrease with increasing mass of the massive star progenitor, increase with increasing energy of the $\mathrm{SN}$ explosion, and increase with increasing amount of $\mathrm{H}$ that is left from the pre-SN H-ingestion event. The amount of $\mathrm{H}$ that is 


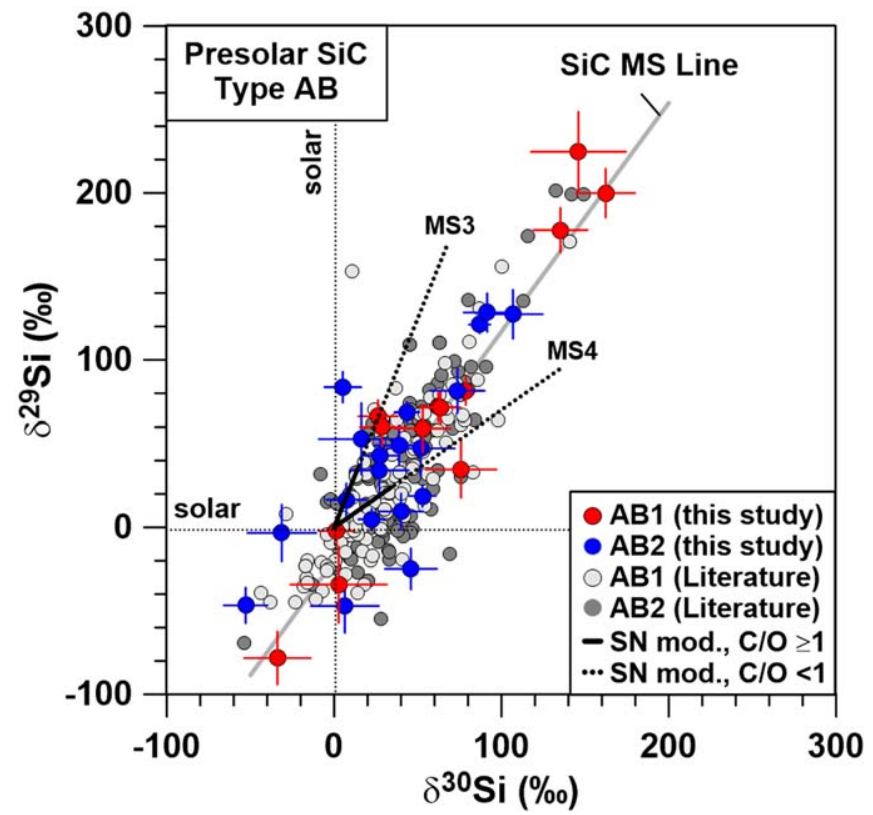

Figure 4. Silicon-isotopic compositions of $32 \mathrm{SiC} \mathrm{AB}$ grains from Murchison separate KJD with $1 \sigma$ errors in $\delta^{30} \mathrm{Si}$ smaller than $30 \%$. AB1 grains $\left({ }^{14} \mathrm{~N} /{ }^{15} \mathrm{~N}<440\right)$ are shown in red and $\mathrm{AB} 2$ grains $\left({ }^{14} \mathrm{~N} /{ }^{15} \mathrm{~N} \geqslant 440\right)$ in blue. Errors are $1 \sigma$. Literature data of $\mathrm{SiC} \mathrm{AB}$ grains (Hoppe et al. 1994, 1996a, 2010; Huss et al. 1997; Amari et al. 2001b; Lin et al. 2002; Marhas et al. 2008; Liu et al. 2017a, 2017b, 2018) are given in gray for comparison. The solar system $\mathrm{Si}$-isotopic composition is shown by the dashed lines. Predictions for the two SN mixing models from Figure 2 with the envelope composition of a $15 M_{\odot}$ SN (Pignatari et al. 2013; models MS 3 and MS4) are shown as black lines. Mixtures with ${ }^{14} \mathrm{~N} /{ }^{15} \mathrm{~N}>100$ are shown as dotted lines and those having ${ }^{14} \mathrm{~N} /{ }^{15} \mathrm{~N}>440$ as solid lines.

ingested in the He shell is extremely uncertain because the massive star progenitor is based on a one-dimensional model, while $\mathrm{H}$-ingestion events require multi-dimensional hydrodynamic simulations (e.g., Stancliffe et al. 2011; Herwig et al. 2014; Woodward et al. 2015). We therefore consider SN models with a factor of 20 as a range of $\mathrm{H}$ enrichment. Finally, the overlying $\mathrm{He} / \mathrm{C}$ zone, which extends to $9.23 M_{\odot}$, still carries milder explosive $\mathrm{H}$-burning signatures within a $\mathrm{C}$-rich region at the bottom.

We examine five different mixing scenarios to compare them directly with the isotopic compositions of $\mathrm{AB} 1$ and $\mathrm{AB} 2$ grains (Table 2). In each, we mix material from the combined $\mathrm{O} /$ nova and $\mathrm{He} / \mathrm{C}$ zones with material in the stellar envelope in varying proportions. Scenarios MS1 and MS2 use the 25T-H and 25TH10 models, respectively. For scenarios MS3 and MS4, we use the $\mathrm{O} /$ nova and $\mathrm{He} / \mathrm{C}$ zone material from the same two models, but take the envelope composition from the $15 M_{\odot} \mathrm{SN}$ model 15r of Pignatari et al. (2013), which is based on the same stellar code, to mimic the envelope compositions of lower mass $\mathrm{SNe}$. Lower mass $\mathrm{SNe}$ have lower ${ }^{14} \mathrm{~N} /{ }^{15} \mathrm{~N}$ and ${ }^{26} \mathrm{Al} /{ }^{27} \mathrm{Al}$ ratios in their envelopes than the more massive $\mathrm{SNe}$, which gives better fits to many of the combined $\mathrm{N}$ - and Al-isotope data (see below). In scenario MS5, we take the interior composition from model 25T-H20, and the envelope composition from model 15r. Carbon-, N-, and Al-isotopic compositions of the combined $\mathrm{O} /$ nova and $\mathrm{He} / \mathrm{C}$ zones and of the envelope for the five mixing scenarios are given in Table 2. The SN model predictions shown in Figures 2 and 3 consider correction factors of 3 for ${ }^{12} \mathrm{C} /{ }^{13} \mathrm{C}$ and 5 for ${ }^{26} \mathrm{Al} /{ }^{27} \mathrm{Al}$ for the

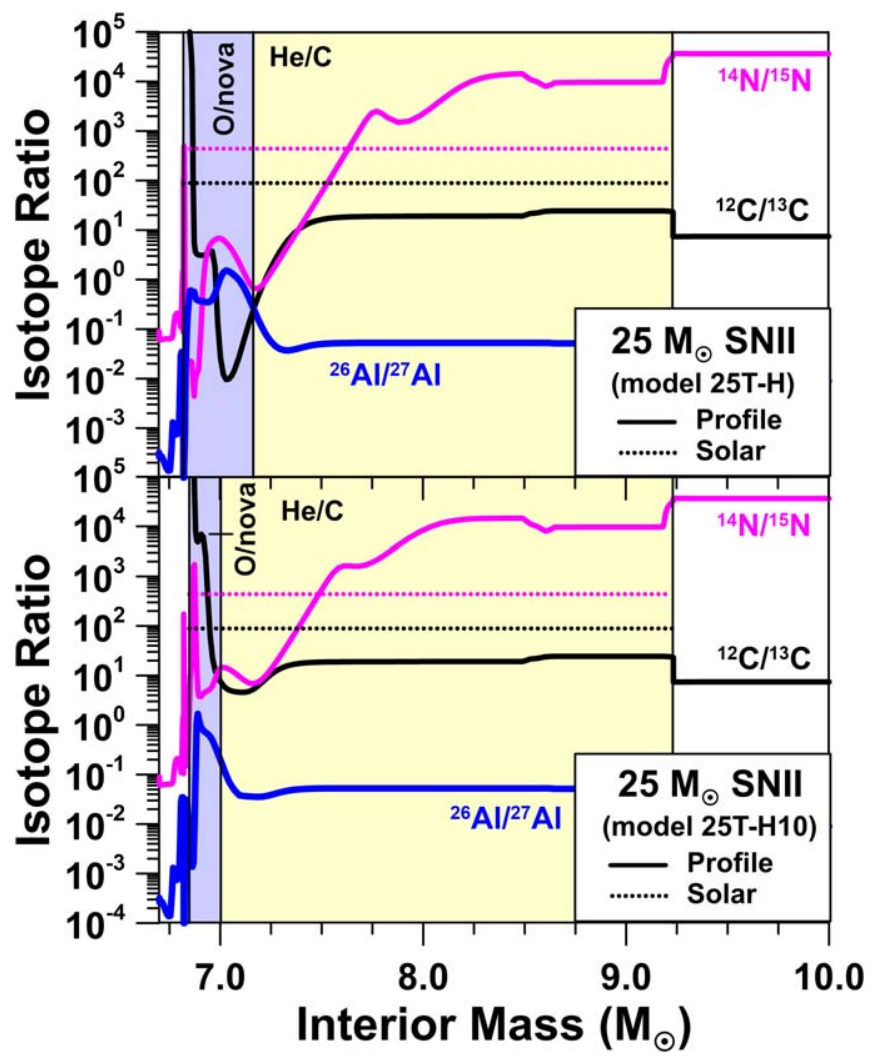

Figure 5. Profiles of ${ }^{12} \mathrm{C} /{ }^{13} \mathrm{C},{ }^{14} \mathrm{~N} /{ }^{15} \mathrm{~N}$, and ${ }^{26} \mathrm{Al} /{ }^{27} \mathrm{Al}$ ratios in the interior of a $25 M_{\odot}$ SN according to models $25 \mathrm{~T}-\mathrm{H}$ and 25T-H10 of Pignatari et al. (2015). The yellow and blue areas denote the $\mathrm{He} / \mathrm{C}$ and $\mathrm{O} /$ nova zones, respectively. The $\mathrm{O}$ /nova zone has experienced explosive $\mathrm{H}$ burning and shows local enrichments in ${ }^{13} \mathrm{C},{ }^{15} \mathrm{~N}$, and ${ }^{26} \mathrm{Al}$.

combined $\mathrm{O} /$ nova and $\mathrm{He} / \mathrm{C}$ zone compositions (see Table 2 and below).

The $\mathrm{C}$ and $\mathrm{N}$ data of both $\mathrm{AB} 1$ and $\mathrm{AB} 2$ grains are well reproduced by our mixing models if the ${ }^{12} \mathrm{C} /{ }^{13} \mathrm{C}$ ratio in the combined $\mathrm{O} /$ nova and $\mathrm{He} / \mathrm{C}$ zones is reduced by a factor of 3, which is within present model uncertainties. Indeed, the ${ }^{13} \mathrm{C}$ abundance is strongly affected by how the $\mathrm{H}$ ingestion forms and develops, and by the following $\mathrm{SN}$ explosion energy. For instance, the ${ }^{12} \mathrm{C} /{ }^{13} \mathrm{C}$ ratio of the $\mathrm{O} /$ nova zone in model $25 \mathrm{~T}-\mathrm{H}$ $(0.083)$ is about a factor of 400 lower than that of model 25T$\mathrm{H} 10$ (35.4), while the ${ }^{14} \mathrm{~N} /{ }^{15} \mathrm{~N}$ ratio varies much less $(3.5$ versus 5.9; Figure 5), demonstrating how sensitive the ${ }^{12} \mathrm{C} /{ }^{13} \mathrm{C}$ ratio is to (local) variations in $\mathrm{H}$ concentration. Furthermore, the amount of ${ }^{13} \mathrm{C}$ made by $\mathrm{H}$-ingestion, before the $\mathrm{SN}$ explosion, depends on several details of the event, such as the amount of $\mathrm{H}$ and the speed with which $\mathrm{H}$ is ingested. Multidimensional hydrodynamics models for $\mathrm{H}$ ingestion in massive stars at solar-like metallicity are required to provide this information and the respective stellar structure response. Models are already available for ingestion of $\mathrm{H}$ into the $\mathrm{He}$ shell in AGB stars, post-AGB stars, and in rapidly accreting white dwarfs (e.g., Stancliffe et al. 2011; Herwig et al. 2014; Denissenkov et al. 2019). On the other hand, the first hydrodynamics simulations are only becoming available now for $\mathrm{H}$-ingestion in massive stars, and only at zero metallicity (Clarkson et al. 2018). Therefore, our results will be extremely important to constrain the next generation of $\mathrm{H}$ ingestion and $\mathrm{SN}$ explosion models. The models also reproduce the weak positive correlation between ${ }^{12} \mathrm{C} /{ }^{13} \mathrm{C}$ and ${ }^{14} \mathrm{~N} /{ }^{15} \mathrm{~N}$ seen in the 
Table 2

Supernova Mixing Scenarios and Their End Member Compositions

\begin{tabular}{|c|c|c|c|c|c|}
\hline Mixing Scenario & MS1 & MS2 & MS3 & MS4 & MS5 \\
\hline Model $\mathrm{O} /$ nova $+\mathrm{HeC}$ & $25 \mathrm{~T}-\mathrm{H}$ & 25T-H10 & $25 \mathrm{~T}-\mathrm{H}$ & $25 \mathrm{~T}-\mathrm{H} 10$ & $25 \mathrm{~T}-\mathrm{H} 20$ \\
\hline Model Envelope & $25 \mathrm{~T}-\mathrm{H}$ & 25T-H10 & $15 \mathrm{r}$ & $15 r$ & $15 r$ \\
\hline${ }^{12} \mathrm{C} /{ }^{13} \mathrm{C}_{\text {int }}{ }^{\mathrm{a}}$ & 7.3 & 16.3 & 7.3 & 16.3 & 18.9 \\
\hline${ }^{12} \mathrm{C} /{ }^{13} \mathrm{C}_{\text {int }} / 3^{\mathrm{b}}$ & 2.4 & 5.4 & 2.4 & 5.4 & 6.3 \\
\hline${ }^{12} \mathrm{C} /{ }^{13} \mathrm{C}_{\mathrm{env}}{ }^{\mathrm{c}}$ & 7.6 & 7.6 & 18.9 & 18.9 & 18.9 \\
\hline${ }^{14} \mathrm{~N} /{ }^{15} \mathrm{~N}_{\mathrm{int}}{ }^{\mathrm{a}}$ & 5.2 & 35 & 5.2 & 35 & 119 \\
\hline${ }^{14} \mathrm{~N} /{ }^{15} \mathrm{~N}_{\mathrm{env}}{ }^{\mathrm{c}}$ & 36100 & 36100 & 4270 & 4270 & 4270 \\
\hline${ }^{26} \mathrm{Al} /{ }^{27} \mathrm{Al}_{\text {int }}{ }^{\mathrm{a}}$ & 0.25 & 0.10 & 0.25 & 0.10 & 0.047 \\
\hline${ }^{26} \mathrm{Al} /{ }^{27} \mathrm{Al}_{\text {int }} / 5^{\mathrm{d}}$ & 0.05 & 0.02 & 0.05 & 0.02 & $9.4 \times 10^{-3}$ \\
\hline${ }^{26} \mathrm{Al} /{ }^{27} \mathrm{Al}_{\mathrm{env}}{ }^{\mathrm{c}}$ & $8.6 \times 10^{-3}$ & $8.6 \times 10^{-3}$ & $5.2 \times 10^{-4}$ & $5.2 \times 10^{-4}$ & $5.2 \times 10^{-4}$ \\
\hline
\end{tabular}

Notes.

${ }^{\text {a }}$ Composition of combined $\mathrm{O} /$ nova and $\mathrm{He} / \mathrm{C}$ zones.

${ }^{\mathrm{b}}$ Used in Figure 2.

c Envelope composition.

${ }^{\mathrm{d}}$ Used in Figure 3.

data of $A B$ grains (Figure 2). AB1 grain KJD-134b, which has the highest ${ }^{12} \mathrm{C} /{ }^{13} \mathrm{C}$ and lowest ${ }^{14} \mathrm{~N} /{ }^{15} \mathrm{~N}$ of the grains presented here, does not follow this trend, which we discuss below. Our mixing models can also account for the combined ${ }^{26} \mathrm{Al} /{ }^{27} \mathrm{Al}$ and ${ }^{14} \mathrm{~N} /{ }^{15} \mathrm{~N}$ data of most $\mathrm{AB}$ grains if the ${ }^{26} \mathrm{Al} /{ }^{27} \mathrm{Al}$ ratio from the combined $\mathrm{O} /$ nova and $\mathrm{He} / \mathrm{C}$ zones is decreased by a factor of 5 . The ${ }^{26} \mathrm{Al} /{ }^{27} \mathrm{Al}$ ratio depends sensitively on the interplay of ${ }^{26} \mathrm{Al}$ production by ${ }^{25} \mathrm{Mg}(\mathrm{p}, \gamma){ }^{26} \mathrm{Al}$ and destruction of ${ }^{26} \mathrm{Al}$ by neutron captures at temperatures $>3 \times 10^{8} \mathrm{~K}$. This leads to relatively large uncertainties on ${ }^{26} \mathrm{Al} /{ }^{27} \mathrm{Al}$ in the $\mathrm{O} /$ nova zone when one-dimensional models are considered and the factor of 5 lower ${ }^{26} \mathrm{Al} /{ }^{27} \mathrm{Al}$ than predicted by models $25 \mathrm{~T}$ $\mathrm{Hx}$ appears conceivable. As for ${ }^{13} \mathrm{C}$, the amount of ${ }^{26} \mathrm{Al}$ made during the $\mathrm{H}$-ingestion event is also still quite uncertain. Again, while the combined H-burning and He-burning nucleosynthesis in pre-supernova and explosive conditions is an anomalous feature measured in presolar grains that can be captured from the one-dimensional models used in this work, these results will be important for the next generation of three-dimensional $\mathrm{H}$ ingestion and $\mathrm{SN}$ explosion models. The mixing models predict a negative correlation between ${ }^{26} \mathrm{Al} /{ }^{27} \mathrm{Al}$ and ${ }^{14} \mathrm{~N} /{ }^{15} \mathrm{~N}$, with a larger scatter in ${ }^{26} \mathrm{Al} /{ }^{27} \mathrm{Al}$ for higher ${ }^{14} \mathrm{~N} /{ }^{15} \mathrm{~N}$ if $\mathrm{SNe}$ with a range of masses are considered. Most of our $\mathrm{AB}$ grain data are encased by mixing models SM1-5 (Figure 3). The lower bound of these models in Figure 3, defined by mixing model SM3, would be shifted to lower ${ }^{26} \mathrm{Al} /{ }^{27} \mathrm{Al}$ ratios if we were to also consider the envelope composition from the $12 M_{\odot}$ SN model of Woosley \& Heger (2007), which has ${ }^{14} \mathrm{~N} /{ }^{15} \mathrm{~N}=2610$ and ${ }^{26} \mathrm{Al} /{ }^{27} \mathrm{Al}=4.4 \times 10^{-4}$; with this, only AB1 grain KJD-134b and AB2 grain KJD-148, which has the highest ${ }^{14} \mathrm{~N} /{ }^{15} \mathrm{~N}$ ratio, would not be covered by our mixing models. The moderate negative correlation between ${ }^{26} \mathrm{Al} /{ }^{27} \mathrm{Al}$ and ${ }^{14} \mathrm{~N} /{ }^{15} \mathrm{~N}$ for $\mathrm{AB} 1$ grains, which was similarly observed by Liu et al. (2017a), is in line with our SN mixing model predictions.

The $\mathrm{C}, \mathrm{N}$, and $\mathrm{Al}$ isotope data of grain KJD-134b are compatible with those of $\mathrm{X}$ and $\mathrm{C}$ grains and are well reproduced by mixing sublayers from the $\mathrm{O} /$ nova zone alone in model $25 \mathrm{~T}-\mathrm{H} 10$ and by considering a $\mathrm{C}-\mathrm{N}$ fractionation during $\mathrm{SiC}$ condensation of a factor of 50 (see Hoppe et al. 2018b). $\mathrm{C}-\mathrm{N}$ fractionation increases the ${ }^{14} \mathrm{~N} /{ }^{15} \mathrm{~N}$ ratio considerably because of high concentrations of radioactive ${ }^{14} \mathrm{C}$ (half-life
$5700 \mathrm{yr}$ ) in the specific mixture to match the isotope data of grain KJD-134b. Note that ${ }^{14} \mathrm{C}$ concentrations are comparatively low when matter from the whole $\mathrm{O} /$ nova and $\mathrm{He} / \mathrm{C}$ zones is mixed with matter from the envelope, so that in mixing scenarios, MS1-5 ${ }^{14} \mathrm{~N} /{ }^{15} \mathrm{~N}$ ratios would be only slightly affected by $\mathrm{C}-\mathrm{N}$ fractionation, which was therefore ignored.

Our mixing models predict only comparatively small $\mathrm{Si}$ isotope anomalies. Silicon isotope anomalies are generally smaller for a lower progenitor mass for the same $\mathrm{N}$-isotopic ratio. For supersolar ${ }^{14} \mathrm{~N} /{ }^{15} \mathrm{~N}$ ratios (i.e., $\mathrm{AB} 2$ grains), ${ }^{29} \mathrm{Si}$ and ${ }^{30} \mathrm{Si}$ are typically enriched by a few percent. For mixtures having $\mathrm{N}$-isotopic compositions of $\mathrm{AB} 1$ grains, enrichments in ${ }^{29} \mathrm{Si}$ and ${ }^{30} \mathrm{Si}$ are larger, but the magnitude of predicted $\mathrm{Si}$ isotope anomalies is still small compared with those of typical SN X and C grains. This is qualitatively consistent with the $\mathrm{Si}$-isotopic compositions of $\mathrm{AB}$ grains, which plot along the $\mathrm{Si}$ mainstream line (Figure 4). Median $\delta^{29} \mathrm{Si}$ and $\delta^{30} \mathrm{Si}$ values of our $\mathrm{AB}$ grains grains with errors in $\delta^{30} \mathrm{Si}$ of less than $30 \%$ o are 59\%o and 53\%o (AB1), and 47\%o and 39\%o (AB2), respectively, which is slightly higher than the values of $33 \%$ and $39 \%$ of mainstream grains from the literature (Hynes \& Gyngard 2009).

Given the uncertainties of the production of $\mathrm{Si}$ isotopes in the SN models considered here, especially at the bottom of the $\mathrm{O} /$ nova zone, the shifts toward heavier $\mathrm{Si}$ as plotted in Figure 4 might be even smaller than calculated. The Si mainstream line can be considered a good proxy for the Galactic chemical evolution of $\mathrm{Si}$ isotopes because only small modifications of the initial Si-isotopic compositions of the parent AGB stars of $\mathrm{SiC}$ mainstream grains are predicted for the third dredge-up events (Zinner et al. 2006; Cristallo et al. 2015). The approximately solar to higher than solar ${ }^{29,30} \mathrm{Si} /{ }^{28} \mathrm{Si}$ ratios of mainstream grains, which are older than our solar system, point to AGB parent stars with about solar or supersolar metallicities (Lugaro et al. 2018), a problem that is not finally settled yet. The fact that $\mathrm{AB}$ grains show a similar range of Si-isotopic compositions as mainstream grains suggests similar Si starting compositions of the parent stars and only minor modifications during stellar evolution, as predicted by our SN mixing models. This could imply that the AGB stars and SNe that supplied presolar grains had a similar range of initial compositions. This idea is supported by astronomical observations that show that 
there was essentially no evolution of metallicity in the Milky Way disk during the last 6-7 Gyr (see Lewis et al. 2013).

Decay of radioactive ${ }^{32} \mathrm{Si}$ (half-life $153 \mathrm{yr}$ ) has been invoked to explain the ${ }^{32} \mathrm{~S}$ excesses observed in $\mathrm{SiC} \mathrm{SN}$ grains (Pignatari et al. 2013). Evidence for radiogenic ${ }^{32} \mathrm{~S}$ has been reported for some AB grains (Fujiya et al. 2013; Liu et al. 2017a). In the SN models considered here, neutron-capture reactions are mitigated due to the presence of $\mathrm{H}$ in the Heburning shell, and the predicted ${ }^{32} \mathrm{Si} /{ }^{28} \mathrm{Si}$ ratios are generally low in mixing scenarios SM1-5. Therefore, the missing ${ }^{32} \mathrm{~S}$ excesses in $\mathrm{AB}$ grains reported here are consistent with our mixing models. We note, however, that $\mathrm{S}$ contamination, which is often observed on or around presolar $\mathrm{SiC}$ grains and which cannot be reliably identified in ion images, may mask intrinsic $\mathrm{S}$ isotope anomalies. For this reason, measured S-isotopic compositions may not be very diagnostic, and we therefore do not discuss them in greater detail here.

\subsection{The Diagnostics of Isotopic Compositions of Heavy Elements}

As we have shown above, C-, N-, Al-, and Si-isotopic compositions of $\mathrm{AB} 1$ and $\mathrm{AB} 2$ grains are qualitatively consistent with origins from SNe. In the following, we investigate to which extent our SN mixing models predict signatures of s-process nucleosynthesis in AB grains. Molybdenum, an element that is heavily affected by the s-process, was measured in a large number of presolar $\mathrm{SiC}$ grains, including $\mathrm{AB}$ grains (Liu et al. 2017b, 2018; Stephan et al. 2019). Here, we explore the ${ }^{100} \mathrm{Mo} /{ }^{96}$ Mo ratio and how it relates to the ${ }^{14} \mathrm{~N} /{ }^{15} \mathrm{~N}$ ratios in our $\mathrm{SN}$ mixing models. Molybdenum-100 is essentially a pure r-process isotope, and ${ }^{96} \mathrm{Mo}$ is a pure s-process isotope (Stephan et al. 2019). The Heburning shells of massive stars are expected to show imprints of a mild s-process from the pre-SN phase (Rauscher et al. 2002), and of the n-process from explosive nucleosynthesis (Pignatari et al. 2018). This results in low ${ }^{100} \mathrm{Mo} /{ }^{96} \mathrm{Mo}$ ratios in the $\mathrm{He} / \mathrm{C}$ zone and strongly enhanced ${ }^{100} \mathrm{Mo} /{ }^{96} \mathrm{Mo}$ ratios at the bottom of the $\mathrm{O} /$ nova zone. Integrating over the whole $\mathrm{O} /$ nova and $\mathrm{He} / \mathrm{C}$ zones yields a lower than solar ${ }^{100} \mathrm{Mo} /{ }^{96} \mathrm{Mo}$ ratio; e.g., in model $25 \mathrm{~T}-\mathrm{H} 10$, the ${ }^{100} \mathrm{Mo} /{ }^{96} \mathrm{Mo}$ ratio of the combined $\mathrm{O} /$ nova and $\mathrm{He} / \mathrm{C}$ zones is 0.32 , compared to the solar ratio of 0.584 (Meija et al. 2016). Predicted ${ }^{100} \mathrm{Mo} /{ }^{96} \mathrm{Mo}$ and ${ }^{14} \mathrm{~N} /{ }^{15} \mathrm{~N}$ ratios of our mixing models SM1 and SM2 are displayed in Figure 6. As can be seen from Figure $6,{ }^{100} \mathrm{Mo} /{ }^{96} \mathrm{Mo}$ ratios are positively correlated with ${ }^{14} \mathrm{~N} /{ }^{15} \mathrm{~N}$ ratios. This is because mixtures with low ${ }^{14} \mathrm{~N} /{ }^{15} \mathrm{~N}$ require a higher contribution from the combined $\mathrm{O} /$ nova and $\mathrm{He} / \mathrm{C}$ zones, which leads to lower ${ }^{100} \mathrm{Mo} /{ }^{96} \mathrm{Mo}$ ratios. The ${ }^{100} \mathrm{Mo}$ depletion decreases with increasing $\mathrm{H}$ concentration in models 25T-Hx (Figure 6). Mixtures with ${ }^{14} \mathrm{~N} /{ }^{15} \mathrm{~N}$ ratios characteristic of $\mathrm{AB} 2$ grains are expected to have Mo isotope anomalies of at most a few percent, while for ${ }^{14} \mathrm{~N} /{ }^{15} \mathrm{~N}$ ratios characteristic of $A B 1$ grains, Mo isotope anomalies may reach several 10\% (Figure 6).

Almost half of $\mathrm{AB} 1$ grains show clearly lower than solar ${ }^{100} \mathrm{Mo} /{ }^{96} \mathrm{Mo}$ (Liu et al. 2018), in qualitative agreement with the predictions from our SN mixing models; however, the data do not show a positive correlation between ${ }^{100} \mathrm{Mo} /{ }^{96} \mathrm{Mo}$ and ${ }^{14} \mathrm{~N} /{ }^{15} \mathrm{~N}$, as would be expected (Figure 6). Molybdenum contamination of presolar $\mathrm{SiC}$ grains cannot be excluded (Stephan et al. 2019); however, to which extent grains with normal Mo are affected by Mo contamination is not known. Only two out of 13 AB2 grains show strong depletions in

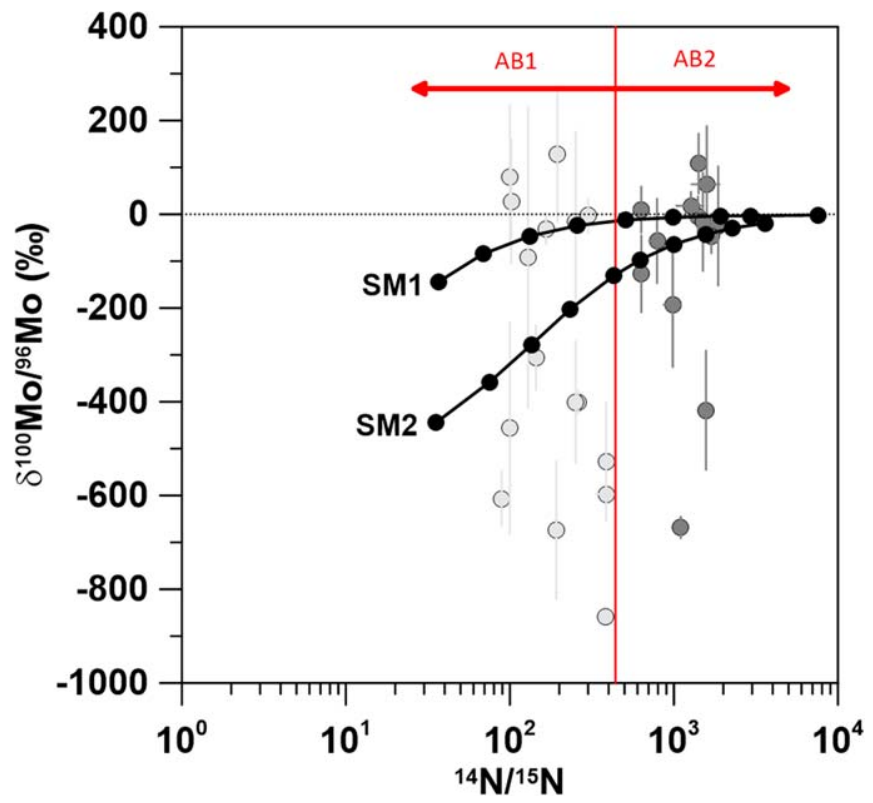

Figure 6. Predictions for $\delta^{100} \mathrm{Mo} /{ }^{96} \mathrm{Mo}$ as a function of ${ }^{14} \mathrm{~N} /{ }^{15} \mathrm{~N}$ for the two SN mixing models from Figure 2 considering the envelope composition of a $25 M_{\odot} \mathrm{SN}$ (models MS1 and MS2). The red vertical line separates AB1 grains from AB2 grains. Molybdenum- and $\mathrm{N}$-isotopic data of $\mathrm{AB} 1$ and $\mathrm{AB} 2$ grains are from Liu et al. (2017b, 2018) and Stephan et al. (2019). Errors are $1 \sigma$.

${ }^{100} \mathrm{Mo}$. The ${ }^{100} \mathrm{Mo} /{ }^{96} \mathrm{Mo}$ ratios of the others are not much different from the solar ratio (Liu et al. 2017b; Stephan et al. 2019; Figure 6), in agreement with the predictions from our SN mixing models. From this and from the isotopic compositions of $\mathrm{C}, \mathrm{N}, \mathrm{Al}$, and $\mathrm{Si}$, we conclude that $\mathrm{SNe}$ must also be considered potential sources of $\mathrm{AB} 2$ grains with only small isotopic anomalies of heavy elements, in addition to J-type $\mathrm{C}$ stars and possibly also post-AGB stars. The two AB2 grains with strong depletions in ${ }^{100} \mathrm{Mo}$ (s-process signature) might be from born-again AGB stars that preserved s-process signatures from the preceding AGB phase and experienced only mild or no i-process production following the $\mathrm{H}$ ingestion, or from massive stars of lower initial mass than what we considered here and weak SN explosion energy, where we expect a more efficient s-process in the He shell.

\subsection{J-type C Stars versus Supernovae as Sources of $A B 2$ Grains}

From the discussion above, an open question that we still cannot answer is how to distinguish AB2 grains from J-type C stars from those from $\mathrm{SNe}$, based on isotopic compositions. We believe that this is beyond the capability of currently available models. Not much is known about the evolution of and nucleosynthesis in J-type C stars (see Introduction), and we have seen that the SN models used here have relevant limitations in terms of the capability of fully capturing the stellar structure feedback and the nucleosynthesis output of $\mathrm{H}$-ingestion events. While current $\mathrm{SN}$ models are useful for exploring qualitative trends, multi-dimensional and selfconsistent $\mathrm{SN}$ models with consideration of $\mathrm{H}$ ingestion into the He-burning shell will allow us to make a more quantitative comparison between model predictions and the isotope data of $\mathrm{AB}$ grains.

An alternative approach to distinguishing AB2 grains from J-type C stars from those from SNe might be to examine the 
dust production efficiencies of these stellar sources. AGB stars are considered the most important source of stardust (Gail \& Hoppe 2010). As pointed out by Liu et al. (2017b), J-type C stars make up about $10 \%-15 \%$ of all C-rich AGB stars (Abia \& Isern 2000), but their dust production efficiency is unknown. In addition to AGB stars, SNe also produce significant amounts of dust (Sugerman et al. 2006; Sarangi et al. 2018), but again, their dust production efficiency is not well constrained. Therefore it is currently not possible to derive a reliable ratio of $\mathrm{SiC}$ dust production in the winds of J-type $\mathrm{C}$ stars to that in CCSN ejecta.

Among the different types of presolar grains, the inferred contributions of $\mathrm{SN}$ grains are $100 \%$ for (rare) $\mathrm{Si}_{3} \mathrm{~N}_{4}$ grains, $\sim 25 \%$ for graphite, $>20 \%$ for oxides/silicates, and only $\sim 4 \%$ for SiC grains (X, C, and AB1 grains; Hoppe 2016; Leitner \& Hoppe 2019). Apparently, the inferred abundance of SN grains among presolar $\mathrm{SiC}$ is distinctly lower than for the other presolar grain types. This raises the question whether additional SN grains might be hidden among the different populations of presolar $\mathrm{SiC}$ grains. If at least some $\mathrm{AB} 2$ grains had an $\mathrm{SN}$ origin, the $\mathrm{SN}$ contribution to presolar $\mathrm{SiC}$ grains could be as high as $>5 \%$. Quantitative models of carbonaceous dust production around born-again AGB stars, J-type C stars, and $\mathrm{SNe}$ are required to provide additional constraints on the relative contribution of stellar sources to the population of AB2 grains.

\section{Summary and Conclusions}

We here presented high-resolution $\mathrm{C}, \mathrm{N}, \mathrm{Al}, \mathrm{Si}$, and $\mathrm{S}$ isotope data of 38 presolar $\mathrm{SiC}$ grains of type $\mathrm{AB}$. The ${ }^{12} \mathrm{C} /{ }^{13} \mathrm{C}$ ratios of the $\mathrm{AB}$ grains in this study are between 1.6 and 16 , the ${ }^{14} \mathrm{~N} /{ }^{15} \mathrm{~N}$ ratios range from 36 to 10,000 , and the ${ }^{26} \mathrm{Al} /{ }^{27} \mathrm{Al}$ ratios are between $10^{-4}$ and 0.13 . Seventeen of the grains are of subtype AB1 $\left({ }^{14} \mathrm{~N} /{ }^{15} \mathrm{~N}<440=\right.$ solar $)$ and 20 of subtype AB2 $\left({ }^{14} \mathrm{~N} /{ }^{15} \mathrm{~N} \geqslant 440\right)$; one grain could not be assigned to one of the subtypes because we lack $\mathrm{N}$ isotope data. Silicon-isotopic compositions fall along the $\mathrm{SiC}$ mainstream line, and the inferred slopes of $\mathrm{AB} 1$ and $\mathrm{AB} 2$ grains are compatible with the slope of mainstream grains. Sulfur-isotopic compositions are solar within $2 \sigma$ uncertainties. The data are compatible with previously obtained isotope data of $\mathrm{AB}$ grains, with the exception that ${ }^{26} \mathrm{Al} /{ }^{27} \mathrm{Al}$ ratios of $\mathrm{AB} 1$ grains span a narrower range.

A comparison with three SN models of Pignatari et al. (2015), who considered $\mathrm{H}$ ingestion into the He shell during the pre-SN phase with $\mathrm{H}$ concentrations between $0.06 \%$ and $1.2 \%$, shows that the isotopic compositions of $\mathrm{AB} 1$ and $\mathrm{AB} 2$ grains can be qualitatively matched when matter from the $\mathrm{O} /$ nova and $\mathrm{He} / \mathrm{C}$ zones is mixed with matter from the envelope and when stellar masses between $12 M_{\odot}$ and $25 M_{\odot}$ are considered. For $\mathrm{AB} 1$ grains, this confirms the conclusions drawn by Liu et al. (2017a). For AB2 grains, Liu et al. (2017b) favored an origin from J-type $\mathrm{C}$ stars. We have shown here that $\mathrm{SNe}$ should be considered as potential sources of a significant fraction of AB2 grains as well, and that born-again AGB stars might also have contributed to the population of AB2 grains.

Because our SN mixing models predict isotopic signatures as observed for J-type $\mathrm{C}$ stars $(\mathrm{C}, \mathrm{N}$, no s-process) it is currently difficult to distinguish between these two types of stellar sources as suppliers of AB2 grains. It is hoped that future modeling of J-type C stars (and born-again AGB stars) as well as improved, i.e., self-consistent and multi-dimensional $\mathrm{SN}$ models with $\mathrm{H}$ ingestion into the He-burning shell will allow us to shed more light on this issue. Both J-type $\mathrm{C}$ stars and $\mathrm{SNe}$ are considered important suppliers of dust, with relative contributions that are currently not known. Quantitative models of carbonaceous dust production around different types of stellar sources could provide additional constraints on the origin of $\mathrm{AB}$ grains.

P.H. thanks the International Space Science Institute (ISSI) in Bern, Switzerland for hospitality and financial support for a visit in 2019 May and June, when a first version of this manuscript was written. We thank Antje Sorowka for her help with SEM analyses, Elmar Gröner and Philipp Schuhmann for technical support on the NanoSIMS, and the anonymous referee for the helpful and constructive review. M.P. and R.J.S. acknowledge the support of STFC, through the University of Hull Consolidated grant ST/R000840/1, and access to the University of Hull HPC Facility, viper. M.P. thanks for support to NuGrid from the ERC Consolidator grant (Hungary) funding scheme (Project RADIOSTAR, G.A. n. 724560), from the "Lendulet-2014" Programme of the Hungarian Academy of Sciences (Hungary), and by the National Science Foundation (NSF, USA) under grant No. PHY-1430152 (JINA Center for the Evolution of the Elements). M.P. and R.J.S. acknowledge the UK network BRIDGCE and the ChETEC COST Action (CA16117), supported by COST (European Cooperation in Science and Technology).

\section{ORCID iDs}

Peter Hoppe (D) https://orcid.org/0000-0003-3681-050X Richard J. Stancliffe (i) https://orcid.org/0000-00026972-9655

Marco Pignatari (ib https://orcid.org/0000-0002-9048-6010

\section{References}

Abia, C., \& Isern, J. 2000, ApJ, 536, 438

Amari, S., Gao, X., Nittler, L. R., \& Zinner, E. 2001a, ApJ, 551, 1065

Amari, S., Hoppe, P., Zinner, E., \& Lewis, R. S. 1992, ApJL, 394, L43

Amari, S., Lewis, R. S., \& Anders, E. 1994, GeCoA, 58, 459

Amari, S., Nittler, L. R., Zinner, E., Lodders, K., \& Lewis, R. S. 2001b, ApJ, 559,463

Bernatowicz, T., Fraundorf, G., Ming, T., et al. 1987, Natur, 330, 728

Besmehn, A., \& Hoppe, P. 2003, GeCoA, 67, 4693

Clarkson, O., Herwig, F., Andrassy, R., et al. 2018, arXiv:1810.12259

Cristallo, S., Straniero, O., Piersanti, L., \& Gobrecht, D. 2015, ApJS, 219, 40

Denissenkov, P. A., Truran, J. W., Pignatari, M., et al. 2014, MNRAS, 442, 2058

Denissenkov, P. A., Herwig, F., Woodward, P., et al. 2019, MNRAS, 488, 4258

Fujiya, W., Hoppe, P., Zinner, E., Pignatari, M., \& Herwig, F. 2013, ApJL, 776, L29

Gail, H.-P., \& Hoppe, P. 2010, in Protoplanetary Dust, ed. D. Apai \& D. S. Lauretta (Cambridge: Cambridge Univ. Press), 27

Groopman, E., Zinner, F., Amari, S., et al. 2015, ApJ, 809, 31

Gyngard, F., Jadhav, M., Nittler, L. R., Stroud, R. M., \& Zinner, E. 2018, GeCoA, 221, 60

Gyngard, F., Nittler, L. R., \& Zinner, E. 2010, M\&PS, 45, A72

Hedrosa, R. P., Abia, C., Busso, M., et al. 2013, ApJL, 768, L11

Herwig, F. 2005, ARA\&A, 43, 435

Herwig, F., Woodward, P. R., Lin, P.-H., Knox, M., \& Fryer, C. 2014, ApJL, 792, L3

Herwig, F., Pignatari, M., Woodward, P. R., et al. 2011, ApJ, 727, 89

Hoppe, P. 2016, in Handbook of Supernovae, ed. A. W. Alsabti \& P. Murdin (Berlin: Springer),

Hoppe, P., Amari, S., Zinner, E., Ireland, T., \& Lewis, R. S. 1994, ApJ, 430,870

Hoppe, P., Leitner, J., Gröner, E., et al. 2010, ApJ, 719, 1370

Hoppe, P., Leitner, J., \& Kodolányi, J. 2018a, ApJ, 869, 47 
Hoppe, P., Pignatari, M., \& Amari, S. 2019a, in 50th Lunar and Planetary Science Conf. (Houston, TX: Lunar and Planetary Institute)

Hoppe, P., Pignatari, M., \& Amari, S. 2019b, in Nuclei in the Cosmos XV, Vol. 219, ed. A. Formicola et al. (Cham: Springer),

Hoppe, P., Pignatari, M., Kodolányi, J., Gröner, E., \& Amari, S. 2018b, GeCoA, 221, 182

Hoppe, P., Strebel, R., Eberhardt, P., Amari, S., \& Lewis, R. S. 1996a, GeCoA, 60,883

Hoppe, P., Strebel, R., Eberhardt, P., Amari, S., \& Lewis, R. S. 1996b, Sci, 272, 1314

Hoppe, P., Strebel, R., Eberhardt, P., Amari, S., \& Lewis, R. S. 2000, M\&PS, 35,1157

Hoppe, P., Annen, P., Strebel, R., et al. 1997, ApJL, 487, L101

Huss, G. R., Hutcheon, I. D., \& Wasserburg, G. J. 1997, GeCoA, 61, 5117

Hynes, K. M., \& Gyngard, F. 2009, in 40th Lunar and Planetary Science Conf. (Houston, TX: Lunar and Planetary Institute), 1198

Jose, J., \& Hernanz, M. 1998, ApJ, 494, 680

José, J., \& Hernanz, M. 2007, M\&PS, 42, 1135

Käppeler, F., Gallino, R., Bisterzo, S., \& Aoki, W. 2011, RvMP, 83, 157

Leitner, J., \& Hoppe, P. 2019, NatAs, 3, 725

Lewis, K. M., Lugaro, M., Gibson, B. K., \& Pilkington, K. 2013, ApJL, 768, L19

Lewis, R. S., Amari, S., \& Anders, E. 1994, GeCoA, 58, 471

Lin, Y., Amari, S., \& Pravdivtseva, O. 2002, ApJ, 575, 257

Lin, Y., Gyngard, F., \& Zinner, E. 2010, ApJ, 709, 1157

Liu, N., Nittler, L. R., Alexander, C. M. O. D., et al. 2016, ApJ, 820, 140

Liu, N., Nittler, L. R., Pignatari, M., Alexander, C. M. O. D., \& Wang, J. 2017a, ApJL, 842, L1

Liu, N., Stephan, T., Boehnke, P., et al. 2017b, ApJL, 844, L12

Liu, N., Stephan, T., Boehnke, P., et al. 2018, ApJ, 855, 144

Liu, N., Stephan, T., Cristallo, S., et al. 2019, ApJ, 881, 28

Lugaro, M., Karakas, A. I., Petõ, M., \& Plachy, E. 2018, GeCoA, 221, 6

Mahon, K. I. 1996, IGRv, 38, 293

Marhas, K. K., Amari, S., Gyngard, F., Zinner, E., \& Gallino, R. 2008, ApJ, 689,622
Marty, B., Chaussidon, M., Wiens, R. C., Jurewicz, J. G., \& Burnett, D. S. 2011, Sci, 332, 1533

Meija, J., Coplen, T. B., Berglund, M., et al. 2016, PApCh, 88, 293

Messenger, S., Keller, L. P., Stadermann, F., Walker, R. M., \& Zinner, E. 2003, Sci, 300, 105

Nittler, L. R. 1996, PhD thesis, Washington Univ., St. Louis

Nittler, L. R., Alexander, C. M. O. D., Liu, N., \& Wang, J. 2018, ApJL, $856, \mathrm{~L} 24$

Nittler, L. R., Amari, S., Zinner, E., Woosley, S. E., \& Lewis, R. S. 1996, ApJL, 462, L31

Nittler, L. R., \& Hoppe, P. 2005, ApJL, 631, L89

Ohnaka, K., \& Tsuji, T. 1999, A\&A, 345, 233

Pignatari, M., Hoppe, P., Trappitsch, R., et al. 2018, GeCoA, 221, 37

Pignatari, M., Zinner, E., Bertolli, M. G., et al. 2013, ApJL, 771, L7

Pignatari, M., Zinner, E., Hoppe, P., et al. 2015, ApJL, 808, L43

Pignatari, M., Herwig, F., Hirschi, R., et al. 2016, ApJS, 225, 24

Rauscher, T., Heger, A., Hoffman, R. D., \& Woosley, S. E. 2002, ApJ, 576,323

Sarangi, A., Matsuura, M., \& Micelotta, E. R. 2018, SSRv, 214, 63

Sengupta, S., Izzard, R. G., \& Lau, H. H. B. 2013, A\&A, 559, A66

Stancliffe, R. J., Dearborn, D. S. P., Lattanzio, J. C., Heap, S. A., \& Campbell, S. W. 2011, ApJ, 742, 121

Stephan, T., Trappitsch, R., Hoppe, P., et al. 2019, ApJ, 877, 101

Sugerman, B. E. K., et al. 2006, Sci, 313, 196

Wiescher, M., Görres, J., Uberseder, E., Imbriani, G., \& Pignatari, M. 2010, ARNPS, 60, 381

Woodward, P. R., Herwig, F., \& Lin, P.-H. 2015, ApJ, 798, 49

Woosley, S. E., \& Heger, A. 2007, PhR, 442, 269

Xu, Y., Zinner, E., Gallino, R., et al. 2015, ApJ, 799, 156

York, D. 1969, E\&PSL, 5, 320

Zinner, E. 2014, in Meteorites and Cosmochemical Processes, ed. A. M. Davis (Amsterdam: Elsevier), 181

Zinner, E., Nittler, L. R., Gallino, R., et al. 2006, ApJ, 650, 350

Zinner, E., Amari, S., Guinness, R., et al. 2007, GeCoA, 71, 4786 